Europe's Journal of Psychology, 7(2), pp. 241-260

www.ejop.org

The differential impact of prognostic and process expectations versus panic severity on depressive symptoms in panic disorder with agoraphobia

Theodora E. Katerelos

University of Quebec in Montreal, Quebec, Canada

Michel Perreault

McGill University and Douglas Mental Health University Institute, Canada

\title{
Claude Bélanger
}

University of Quebec in Montreal

McGill University and Douglas Mental Health University Institute, Canada

\section{André Marchand}

University of Quebec in Montreal

Research Centre Fernand-Séguin, LH. Lafontaine Hospital, Canada

John Pecknold

McGill University and Douglas Mental Health University Institute, Canada

\section{Abstract}

Background: Panic disorder with agoraphobia (PDA) co-occurs highly with depression. Greater panic symptoms, agoraphobic avoidance, comorbidity and anxiety sensitivity have all been linked to depressive symptoms in PDA. Psychotherapy research has historically linked prognostic and process expectationsto symptom severity. However, no study has explored the relationship of expectancies and depressive symptoms in PDA. The purpose of the present study was to determine the extent to which expectations and panic symptomatology have a differential impact on depressive symptoms in PDA above and beyond the influence of anxiety sensitivity and secondary Axis I comorbid disorders (e.g., generalized anxiety disorder, social anxiety disorder) just prior to entering therapy. Method: The relationship between depressive symptoms, panic symptomatology and expectancies (i.e., prognostic and process expectations) was 
investigated in 74 patients with a primary diagnosis of panic disorder with agoraphobia. It was hypothesized that expectancy measures rather that panic symptomatology would add to the prediction of depressive symptoms beyond the effects of secondary comorbid disorders and anxiety sensitivity. Results: The findings showed that prognostic and process expectations accounted for significant variance in depressive symptoms beyond that predicted by anxiety sensitivity and secondary Axis I comorbid disorders. In addition, PDA symptomatology failed to significantly enter into our prediction model. Conclusions: These results suggest that expectancies have a greater impact on depressive symptoms in PDA regardless of the secondary comorbid disorders and severity of symptoms in PDA. Implications of these findings on the treatment of PDA are discussed.

Key words: prognostic expectations, process expectations, anxiety expectancy, anxiety sensitivity, panic disorder with agoraphobia, depression.

\section{Introduction}

Panic disorder is frequently accompanied by agoraphobia (American Psychological Association, 1994). Panic disorder is a sudden onset of intense apprehension or doom associated with four out of thirteen symptoms such as shortness of breath, palpitations, chest pain or discomfort, choking or smothering sensations, and fear of "going crazy" or losing control (American Psychiatric Association, 1994). Agoraphobia is a fear about being in places or situations from which escape might be difficult (or embarrassing) or in which help may not be available in the event of having a panic attack (American Psychiatric Association, 1994). The co-occurrence of panic disorder with agoraphobia (PDA) and depression has been demonstrated in numerous studies (Andrade, Eaton, \& Chilcoat, 1994; Regier, Rae, Narrow, Kaelber \& Schazberg, 1998; Renneberg, Chambless, \& Gracely, 1992; Tsao, Lewin, \& Craske, $1998)$. For instance, Renneberg and colleagues (1992) reported that $15 \%$ of the PDA participants in their study suffered from major depression and $27 \%$ from dysthymia(a chronic depression that is less severe than major depressive disorder) (American Psychiatric Association, 1994). Higher levels of depressive symptoms may also be related to avoidance behaviour in anxiety disorders (Cassano, Perugi, Musetti, \& Akiskal, 1989; Cox, Endler, \& Swinson, 1995; Parker, Wilhelm, Mitchell, Austin, Roussos, \& Gladstone, 1999; Telch, Brouillard, Telch, Agras, and Taylor, 1989). Telch and associates (1989) found that subjects with PDA had significantly greater levels of depression as measured by the Beck Depression Inventory (BDI; Beck, Steer, \& Brown 1996) than those with just panic disorder. Chambless (1985) also reported significant links between BDI scores and patients suffering from agoraphobia. Avoidance behaviours may also act as risk factors in the onset of depression. For instance, Parker 
and colleagues (1999) found that social avoidance tends to precede the onset of major depression. In addition, Regier and colleagues (1998) discovered that the average age of onset of agoraphobia and comorbid depression is much younger for agoraphobia (i.e., 15.7 years old) than the age of onset for major depression (i.e., 24.1 years old). This suggests that avoidance behaviours in PDA may precede and precipitate the onset of a comorbid major depressive episode.

A stronger association has also been detected between anxiety expectancy (i.e., the extent to which patients expect to experience anxiety) and avoidance behaviour, rather than with the occurrence of panic attacks and avoidance (e.g., Cox, Endler and Swinson, 1995; Cox, Swinson, Norton and Kuch, 1991; Craske, Rapee, \& Barlow, 1988; Telch, et al., 1989; Whittal \& Goetsch, 1997). For instance, Telch and colleagues (1989) found that panic expectancy was the best predictor of agoraphobic avoidance in PDA. Moreover, in contrast to panic disorder without agoraphobia, PDA patients reported more anticipation of panic. This implies that as expectation of panic increases, so does avoidance. This finding is also supported by Craske and Barlow's (1988) hypothesis suggesting that there is a greater relationship between avoidance behaviour and anxiety expectancy rather than with the occurrence of panic attacks. Similarly, depressive symptoms in PDA patients are also considered predictors of panic expectancy. For instance, Whittal and Goetsch (1997) found that higher scores on the BDI predicted higher expectations of panic prior to entering a grocery store.

Similar to the research results on anxiety expectancy, other studies have also demonstrated a relationship between high levels of anxiety sensitivity and avoidance behaviour. More specifically, individuals with high anxiety sensitivity expect that their anxiety sensations will cause them somatic, psychological or social harm (Reiss, 1991; Reiss, Peterson, Gursky \& McNally, 1986). This suggests that negative expectations related to sensations of anxiety in panic disorder may lead to greater avoidance. According to Reiss' expectancy theory (Reiss, 1991; Reiss et al., 1986), anxiety sensitivity can precede panic attacks and may be a risk factor for panic disorder with agoraphobia (Reiss, 1991; Reiss et al., 1986; Maller \& Reiss, 1992). Once again, studies have also linked depression to greater fear of anxiety sensations (Taylor, Koch, Woody,\& McLean, 1996). Taylor and associates (1996) detected high levels of anxiety sensitivity in individuals with depression. Schmidt, Lerew and Joiner (1998) found that high scores on the Anxiety Sensitivity Index (ASI; Reiss et al., 1986) were more likely to exacerbate depressive symptoms in the context of anxiety. Cox, Enns, Freeman and Walker (2001) demonstrated that patients who were no longer diagnosed with a major depressive episode after a one year follow-up, continued to score high on the ASI. In contrast to normal controls, formerly depressed patients 
displayed significantly higher levels of anxiety sensitivity even though there was no difference between the two groups on level of depressed mood.

The above studies on anxiety expectancy and anxiety sensitivity suggest a cognitive style that may be different in patients suffering from PDA alone versus those with PDA and high symptoms of depression. Since depression has been previously linked with negative automatic thinking, including pessimistic cognitions (Nekanda-Trepka, Bishop, \& Blackburn, 1983; see Telch, 1988), low self-esteem, negative self-concepts and expectations (Bachelor, Bleau, \& Raymond, 1996; Nekanda-Trepka et al., 1983), it would be important to examine to what extent overall expectations and panic symptomatology impact on PDA clients with depressive symptoms. By identifying these predictors, the treatment may be appropriately adapted to also meet the needs of those with PDA and comorbid depression.

Studies have found evidence on the effects of panic symptomatology, anxiety expectancy and sensitivity on depressive symptoms in PDA. However, no studies to our knowledge, have examined the role of process expectations on depressive symptoms in PDA. Process expectations include (1) participant roles referring to anticipations regarding therapist characteristics, and therapist and client behaviour and attitudes expected to be displayed throughout therapy, and (2) anticipations referring to therapeutic process and procedures. The negative cognitive style in depressive clients may also impact on their expectations of what therapy will involve.

The majority of the studies conducted on process expectations are found in counselling research (e.g., Kunkel, Hector, Gongóra Coronado \& Castillo Vales, 1989; Mezydlo Subich \& Coursol, 1985; Tinsley, Bowman, \& Ray, 1988; Tinsley, Brown, St. Aubin, \& Lucek, 1984; Tinsley, Workman \& Kass, 1980). Al-Darmaki and Kivlighan (1993) examined the effect of expectation congruence on the client-counsellor relationship and on their working alliance. The findings suggested that increased congruence in their expectations with regards to the therapeutic relationship is a good predictor of alliance. Examining the level of congruence in clients' process expectations to the treatment they are about to participate in, may provide information on how to modify the treatment to address their needs or their incongruent expectancies at the beginning of therapy.

This study examines the differential impact of panic symptomatology and expectancy on depressive symptoms in PDA. The association between depressive symptoms, panic symptomatology, prognostic expectancies (anxiety sensitivity, anxiety expectancy and avoidance expectancy), and process expectations was explored. Next, the differential impact of panic symptomatology and expectancies 
on depressive symptoms was examined above and beyond the influence of secondary Axis I disorders (including depression) and anxiety sensitivity as measured by the ASI (Reiss et al., 1986). As previously indicated, the ASI has already been detected as a determinant of depression in several studies. We hypothesized that expectancy measures rather that panic symptomatology would add to the prediction of depressive symptoms beyond the effects of secondary comorbid disorders and anxiety sensitivity.

\section{Method}

\section{Participants}

The sample consisted of 76 participants (26 males, 50 females) with a principal DSMIV (American Psychiatric Association, 1994) diagnosis of panic disorder with agoraphobia (PDA). The mean age of the sample was 40.1 years (SD $=10.1$ 1; range: 19 - 65) and the mean education level was 11.9 years (SD $=3.46)$. The average number of years of marriage or cohabitation was 11.39 years (SD = 10.99). Approximately $39.5 \%$ of the patients were married, $38.2 \%$ were cohabiting, $17.1 \%$ were single, $2.6 \%$ were separated or divorced and $2.6 \%$ were widowed. Most participants (68.4\%) took psychotropic medication.

Participants were recruited from two specialized outpatient anxiety disorder clinics in Montreal: the Douglas Anxiety Clinic $(n=13)$ and the outpatient clinic at Louis-H. Lafontaine Hospital ( $n=16$ ). Participants were also recruited from advertisements in the local newspapers $(n=47)$. Analyses of variance demonstrated no significant difference between clients referred from either of the two clinics and those referred from the local newspapers on any sociodemographic, expectancy, or symptom measure $(p>.05)$.

Patients included in the study met the following criteria: (a) a primary DSM-IV diagnosis of PDA assigned by a psychiatrist; (b) a primary diagnosis of PDA according to the Anxiety Disorders Interview Schedule, for DSM-IV, Lifetime Version (ADIS-IV-L; DiNardo et al., 1994) with a clinical severity rating of 4 or above on a scale ranging from 0 (none) to 8 (very severely disturbing-disabling), (c) a secondary DSMIV axis I diagnosis with an assigned ADIS-IV-L clinical severity rating which ranges from moderate to severely disabling (i.e., 4 to 6) and consists of a rating of 2 or more levels lower than the PDA rating, (d) age between 18 and 65 years, and (e) a mean of at least 1 panic attack per week in the 3 weeks prior to participating in the assessment. Exclusion criteria included: (a) the presence of substance-related, psychotic, and any organic brain conditions; and (b) the presence of any unstable medical condition considered by the evaluating psychiatrist to be mistaken for anxiety 
symptoms (e.g., thyroid disorders, asthma, cardiovascular diseases, etc). The average duration of PDA was 12.8 years (SD = 9.8; range: 1 - 40 years). Patients met criteria for one or more of the following secondary diagnosis: generalized anxiety disorder $(n=20)$, major depressive disorder $(n=10)$, social phobia $(n=6)$, dysthymia $(n=4)$, obsessive compulsive disorder $(n=4)$, specific phobia $(n=4)$, post traumatic stress disorder $(n=4)$, hypochondriasis $(n=3)$, and mania $(n=1)$.

\section{Procedure}

Participants recruited from advertisements in the local newspapers were screened using a brief telephone interview in order to determine suitability. Potential candidates were invited to either one of the clinics to take part in the ADIS-IV-L administered by advanced graduate students in psychology. If the criteria for a primary diagnosis of PDA were satisfied according to the ADIS-IV-L, a psychiatrist subsequently evaluated the participants to confirm the initial diagnosis. Participants completed the questionnaire battery after their diagnosis had been confirmed. Those recruited directly from the clinics had already received a diagnosis of PDA by one of the psychiatrists. They nevertheless received the structured interview with the ADIS-IV-L in order to rule out an additional Axis I primary diagnosis and to confirm the psychiatrist's diagnosis. All participants provided informed consent prior to the structured interview with the ADIS-IV-L. No discrepancies were reported between the ADIS-IV-L diagnosis and that of the psychiatrist.

\section{Measures}

Symptom severity measures. Participants completed a battery of self-reported measures commonly used in PDA research. The following measures on symptom severity have demonstrated acceptable psychometric properties. A French validated version of these questionnaires was utilized in the current study.

The ADIS-IV-L (DiNardo et al., 1994), a structured interview, was administered to assess the differential diagnoses among anxiety disorder categories. It also evaluated the history of the problem, situational and cognitive factors influencing anxiety, detailed symptom ratings and the interviewer's judgment of the degree of distress and interference in functioning associated with a PDA diagnosis.

A validated French version of the Beck Depression Inventory-II (BDI-II; Beck et al., 1996) was administered in the current study to assess the severity of depression over the last two weeks. It is composed of 21 items measuring depressive symptoms on a 4-point scale. The BDI assesses somatic symptoms, mood disturbances and negative cognitions over the past two weeks. Sound psychometric properties have been 
associated with the English version of this measure. In the current study, internal consistency was estimated at .91. There is no validation study for the FrenchCanadian version of the BDI-II that was translated in 1997. The earlier FrenchCanadian versions, the BDI (1961) and BDI 1A (1978), have been validated (Gauthier et al., 1982; Bourque and Beaudette, 1982). We nevertheless chose to administer the French-Canadian version of BDI-II because it is more consistent with the DSM-IV criteria for major depressive disorder than the earlier versions.

The Body Sensations Questionnaire (BSQ; Chambless et al., 1984) and Agoraphobia Cognitions Questionnaire (ACQ; Chambless et al., 1984) assessed severity of cognitive panic symptoms. The BSQ is a 17-item questionnaire that measures level of fear concerning bodily sensations during a panic attack. The $A C Q$ consists of 14 items measuring the frequency of catastrophic thoughts during a panic attack. Both measures are rated on a 5-point Likert-type scale. Coefficient alpha for the BSQ in this study was estimated at .88 and for the ACQ at .77. The psychometric properties of the French-Canadian versions employed in this study are equivalent to those of the English version (Stephenson et al., 1998; Stephenson et al., 1999).

The Mobility Inventory for Agoraphobia-Alone (MIA-A; Chambless et al., 1985) was used to assess the severity of agoraphobic avoidance behavior when the person is alone. This 26-item questionnaire is rated on a 5-point Likert-type scale. This study calculated the coefficient alpha at .92. Psychometric properties of the FrenchCanadian version have been found to be similar to those of the English version (Stephenson et al., 1997).

Beck Anxiety Inventory (BAl; Beck et al., 1988) assessed physical and cognitive symptoms experienced during the past week. This 21 -item questionnaire, rated on a 4-point scale, examines the degree to which participants were affected by their symptoms over the past week. In this study, internal consistency was estimated at 93. Cronbach's alpha of the French-Canadian version administered in this study has been previously calculated at .85 (Freestone, Ladouceur, Thibodeau, Gagnon, Rhéaume, 1994).

Expectancy measures. All expectancy measures for this study were translated into French by the back-translation method (Vallerand, 1989; see Table 1 for overall distribution of all expectancy measures).

Anxiety expectancies: The section on the severity of panic symptoms from the ADISIV-L (Dinardo et al., 1994) was adapted and reformulated into expectations to assess prognostic expectations specifically related to panic-related symptoms. The 
Symptom Expectancy Questionnaire (SEQ) consists of 14 items, rated on a 4-point scale, that measure the extent to which patients expect various panic-related symptoms to be diminished following therapy (e.g., At the end of treatment, I expect my symptoms of dizziness to....) The Cronbach alpha coefficient for the French version of the SEQ (Marcaurelle and Katerelos, 1998) using the current sample was calculated at .92.

Avoidance expectancies: An adaptation of the Mobility Inventory for AgoraphobiaAlone (MIA-A; Chambless et al., 1985) was used to assess prognostic expectations related to the degree to which clients expect their avoidance behavior to persist following therapy (i.e., avoidance expectancy). The same items were administered along with the corresponding 5-point scale. However, the adapted version contains questions reformulated into expectancies (e.g., "After the treatment, I expect to never avoid going to the movies"). With the current French sample and with the items reformulated into expectancies, internal consistency was at .92. This questionnaire will be referred to as the Expectancy Mobility Inventory for Agoraphobia-Alone (EMIA-A; Katerelos et al., 1998).

Process expectations: The Process Expectations Questionnaire (PEQ; i.e., expectations of therapeutic process and procedures and roles of participants and therapist) was devised by the authors and consists of 28 items rated on a 4-point Likert scale (1 = strongly agree to $4=$ strongly disagree) divided into two sub-scales, (1) expectations on the process and procedures of therapy (10 items); (2) role expectations (18 items). Nine out of the ten items on expectations on the process and procedures of therapy were inspired from the Attitudes Towards, and Beliefs about Psychotherapy Questionnaire (ABPQ; Furham and Wardley, 1990), a 40-item questionnaire, with an internal consistency of .70. Items from this questionnaire that were adapted and reformulated into expectations include: 2 items loading highest on the factor conflicts and emotions referring to psychodynamic therapy (PDT) techniques; 4 items related to the factor dealing with what psychotherapy teaches or instructs clients (2 CBT items and 2 PDT); and 1 item referring to the background of psychotherapy sessions themselves (PDT item). The following items that did not load on any factor structures were also included because they were considered relevant to the current study: 1 question referring to exposure to a feared situation (CBT); and 1 item pertaining to the unconscious nature of psychological problems (PDT). Finally, we also added 1 item examining whether clients expected to participate in exercises that would provoke anxiety symptoms (CBT), for a total of 10 items on the process and procedure expectancies. 
The 18 items pertaining to role expectations were inspired from Thoughts about Psychotherapy Survey (TAPS; Kushner and Sher, 1989), the Reactions to Psychotherapy Questionnaire (RPQ; Furham and Wardley, 1990), Psychotherapy Questionnaire (PQ; Zwick and Attkisson, 1984) and the ABPQ, (Furham and Wardley, 1990). Five of the 6 items from the TAPS were adapted and reformulated into expectations from the first of three factors entitled therapist competence and professionalism, and one item was inspired from therapist responsiveness and image concerns. The 6 items adapted and reformulated into expectations from the RPQ include: 3 items loading highest on the factor negative reactions; 2 items associated with understanding; and 1 item loading on active change (i.e., involvement of patient in therapy). Four items were adapted and reformulated into expectations from the PQ: talking with a therapist is much like chatting to a friend; dependence on the therapist; therapeutic advice similar to what a medical doctor does; and immediate therapeutic progress. Two items were added and reformulated into expectations dealing with resistance to change (see ABPQ; Furham and Wardley, 1990) and expectations of the therapist finding solutions for all anxiety-related problems. Internal consistency for the TAPS has been calculated at .87 to .92 (Kushner and Sher, 1989), for the RPQ at .70 (Furham et al., 1992) and for the original $\mathrm{PQ}$ at .85 (Zwick and Attkisson, 1985). The current study estimated the Cronbach alpha for the Process Expectations Questionnaire (PEQ) at .72 (Katerelos, Bélanger et al., 1998).

Control Variable. The Anxiety Sensitivity Index (ASI; Reiss et al., 1986) is a 16-item questionnaire, rated on a 5-point Likert-type scale, that measures fear of anxiety and has been specifically associated with agoraphobia (see Taylor, 1993). Each item assesses concerns about the possible negative consequences of symptoms associated with anxiety. The internal consistency of the questionnaire has been estimated at .88 (Cox et al., 1996) and a two-week test-retest reliability has been computed at .75 (Reiss et al., 1986). Psychometric properties of the French-Canadian version have been found to be similar to those of the English version (Marchand et al., 1999). Internal consistency for the French translation of the ASI was calculated at .82 in this study.

Results

Descriptive statistics for the BDI-II

Scores on the BDI-II were normally distribution with a mean score of 18.99 (SD $=10.94$; range $=2-46$ ). A one-way analysis of variance (ANOVA) revealed a significant 
difference in severity of depressive symptoms in patients suffering from one Axis I disorder $(n=49 ; M=17.15, S D=11.02)$ versus two or more secondary Axis I anxiety and affective disorders $(n=27, M=22.34, S D=10.14) F(1,74)=4.07, p<.05$. Those with two or more Axis I disorders displayed higher levels of depression. No significant relationship was detected between depressive symptoms and duration of PDA ( $r=$ $.08, p>.05$ ) and depressive symptoms and number of panic attacks in the past week $(r=.05, p>$.05).

Predictors of depressive symptoms in PDA

Table 1 presents the means and standard deviations for all expectancy and symptom measures, and the correlation between these measures and the BDI-II. All measures were distributed normally.

Table 1: Overall distribution of expectancy measures and correlations with the BDI-II

\begin{tabular}{|c|c|c|c|c|}
\hline Variables & $r$ with BDI-II & M & $S D$ & Range \\
\hline \multicolumn{5}{|l|}{ symptom } \\
\hline $\mathrm{BSQ}$ & .21 & 50.39 & 14.29 & $17-85$ \\
\hline$A C Q$ & $.29 *$ & 36.76 & 8.85 & $17-60$ \\
\hline MIA-A & .13 & 84.38 & 22.58 & $42-130$ \\
\hline $\mathrm{BAI}$ & $.25^{*}$ & 28.79 & 14.43 & $0-60$ \\
\hline \multicolumn{5}{|c|}{ Expectancies } \\
\hline ASI & $.38^{* * *}$ & 35.39 & 10.55 & $11-59$ \\
\hline SEQ 1 & $-.38^{* * *}$ & 42.08 & 6.12 & $28-54$ \\
\hline EMIA-A & $.33^{* *}$ & 54.93 & 18.76 & $26-114$ \\
\hline PEQ 2 & $-.40^{* * *}$ & 86.24 & 6.99 & 69-105 \\
\hline
\end{tabular}

$n=76 .{ }^{*} p<.05,{ }^{* *} p<.01,{ }^{* * *} p<.001$.

1 Higher scores: clients expect their panic symptoms to diminish after treatment has ended

2 Higher scores: greater congruence with treatment process and procedures and therapist and participant roles 
Hierarchical regression analyses were conducted to examine whether expectancies predicted depressive symptoms in patients suffering from panic disorder with agoraphobia, beyond the effects of PDA symptomatology. Analyses were conducted into four steps: (1) Since comorbidity main effects were detected, comorbidity (i.e., presence or absence) was entered into the first step as a control variable. (2) Similarly, because previous data has demonstrated the ASI as a predictor of depressive symptoms, it was entered into the second step. (3) Symptom measures were entered into the third step in order to ascertain their incremental validity. (4) Finally, expectancy measures were entered in the fourth step to determine the extent to which these measures add to the prediction rating above and beyond the effects of the other measures. Table 2 shows that the ASI added to the prediction model of depressive symptoms in PDA above and beyond that of our control variable. In fact, when the ASI was included in the prediction model, comorbidity failed to enter significantly into the second step. Moreover, the addition of PDA symptom measures did not produce significant increments in the explained variance over that accounted for by the ASI and comorbidity. However, the expectancy measures significantly added to the prediction model of depressive symptoms in PDA. These findings suggest that expectancies are better predictors of depressive symptoms in PDA then measures commonly used to evaluate PDA symptomatology.

Table 2: Hierarchical Regression Analysis of the BDI-II on PDA Symptomatology and Expectancy when Comorbidity and Anxiety Sensitivity are Controlled

\begin{tabular}{|c|c|c|c|c|c|}
\hline Model & Predictor Variables & $R^{2}$ change & $\begin{array}{l}F \text { value for } \\
R^{2} \text { change }\end{array}$ & $d f s$ & $\begin{array}{c}\text { Semi- } \\
\text { partial } R^{2}\end{array}$ \\
\hline \multirow[t]{2}{*}{1} & Comorbidity & $.16^{* *}$ & 6.77 & 2,73 & 1.2 \\
\hline & ASI & & & & $10.4^{* *}$ \\
\hline \multirow[t]{2}{*}{2} & $A C Q$ & .01 & .54 & 2,71 & .06 \\
\hline & $\mathrm{BAl}$ & & & & 1.5 \\
\hline \multirow[t]{3}{*}{3} & $P E Q$ & $.16^{* *}$ & 5.54 & 3,68 & $6.8^{*}$ \\
\hline & SEQ & & & & $4.7^{*}$ \\
\hline & EMIA-A & & & & .08 \\
\hline
\end{tabular}

$n=76 .{ }^{*} p<.05,{ }^{* *} p<.01,{ }^{* * *} p<.001$ 
Hierarchical regression analyses were re-ran in order to determine whether process expectations (PEQ) and prognostic expectations (SEQ) would significantly predict depressive symptoms after controlling for comorbidity and anxiety sensitivity. Comorbidity was entered into the first step followed by the ASI and then the PEQ and SEQ were entered into the final step. This analysis indicated that $5.2 \%$ of the variance in the $\mathrm{BDI}$ was explained by comorbidity $F(1,74)=4.07, p<.05,10.4 \%$ of the variance was accounted for by the $\operatorname{ASI} F(1,73)=9.02, p<.01$, and $16.4 \%$ of the variance was explained by the PEQ and $\operatorname{SEQ} F(2,71)=8.55, p<.001$ accounting for a total of $32.0 \%$ of the variance. These findings suggest that the inclusion of process and prognostic expectancies contribute additional information in predicting depressive symptoms in PDA.

\section{Discussion}

The current study examined the differential effect of PDA symptomatology and expectancies on depressive symptoms above and beyond the influence of secondary Axis I disorders (i.e., anxiety and affective disorders) and anxiety sensitivity. As hypothesized, expectancies predicted depressive symptoms above and beyond the influence of PDA symptomatology, comorbidity and anxiety sensitivity. Moreover, symptom measures failed to enter significantly into the model. This finding suggests that depressive symptoms in PDA, evaluated prior to any therapy, are generally predicted by two or more Axis I disorders, levels of anxiety sensitivity, prognostic expectations and expectations related to the procedures in therapy.

Our findings showed that individuals with high anxiety sensitivity (i.e., expectations about the potential harmfulness of anxiety-related sensations) were more likely to experience depressive symptoms. These findings are consistent with previous studies examining the links between anxiety sensitivity and depression (Cox et al., 2001; Otto et al., 1995; Schmidt et al., 1998; Taylor et al., 1996). These studies detected elevated scores on the ASI in depression with no comorbid anxiety disorders (Cox et al., 2001; Otto et al., 1995; Schmidt et al., 1998; Taylor et al., 1996). Our data suggest that PDA participants with greater fears of their sensations of anxiety, regardless of whether they have another comorbid Axis I disorder, will experience greater depressive symptoms. The current results may have important implications when planning treatment since increased anxiety sensitivity has been previously detected as a negative predictor of response to CBT and pharmacotherapy in panic disorder (Clark et al., 1994). Since PDA patients with increased depressive symptoms also have greater anxiety sensitivity it may be suggested that the addition of depressive symptoms may contribute to a poorer treatment outcome. 
Participants with greater depressive symptoms were also more likely to have low expectations that their symptoms of panic would improve following therapy. Consistent with Seligman's helplessness theory (Seligman, 1975), it may be suggested that expectations of those with depressive symptoms may be more negative due to their pessimistic explanatory style. Depressed individuals do not only internalize and generalize bad events that happen to them, they also tend to believe that these events will remain stable throughout time (see Abramson et al., 1978; Burns and Seligman, 1991). For instance, they may expect that their panic attacks will persist even after a treatment has been administered. Moreover, their pessimistic explanatory style may contribute to their low expectations of beneficial treatment effects. Our results are similar to those of Cohen and colleagues (2001) who examined whether "treatment-specific optimism" (e.g., beliefs about the treatment working) in cancer patients is associated with better mental health at the beginning and at the end of a cancer treatment. They found that patients who had negative expectations regarding their treatment outcome were more likely to have a depressed mood at the beginning and at the end of treatment. They concluded that patients who are not optimistic about the treatment helping them are more likely to have depressive symptoms. These findings may have serious implications since pessimistic expectations regarding treatment outcome may deter PDA patients from participating in therapy if they expect a poor prognosis. Future research should examine the effect of cognitive explanatory styles of PDA patients with depressive symptoms.

Panic disorder with agoraphobia participants whose expectations of the process and procedures of therapy that were congruent with the actual treatment being offered demonstrated lower levels of depressive symptoms. Clients with PDA who demonstrated positive expectancies in terms of their own role in therapy (e.g., participation) and that of the therapist (e.g., expertness of the clinician) also had low depressive symptoms. Low depressive PDA patients may have a more optimistic cognitive-style that positively affects both their expectations of the therapist competency to help them and their expectancy of their personal involvement in the therapy. Depressive symptoms are frequently characterized by low motivation (e.g., inability to perform tasks), negative self-concept (e.g., views self as defective or inadequate), passivity and inactivity (Beck, Rush, Shaw \& Emery, 1979). The above variables may have influenced the manner in which PDA patients with high depressive symptoms expected to behave in therapy.

The current study demonstrated that PDA patients with relatively high depressive symptoms have more overall negative expectations than those with lower depression. Regardless of the severity in PDA symptomatology, cognitions related to 
negative expectancies appeared to be the primary determinants of depressive symptoms in PDA. However, the data are preliminary in nature and most expectancy measures that were utilized were new. Future studies should attempt to replicate these findings. The psychometric properties of the Process Expectations Questionnaire and the Symptom Expectations Questionnaire should undergo further study. Future studies should also examine the extent to which optimistic and pessimistic cognitive styles are linked to the different types of expectations. In addition, their influence on treatment outcome for PDA with depressive symptoms should be further explored since negative cognitive styles in high depressive PDA patients may interfere with a cognitive-behavioral treatment geared for PDA without depression. Finally, although there Eis a greater relationship between negative expectations and depressive symptoms in PDA, regression analyses do not allow us to conclude that expectations explain the variance in depression. On the contrary, it is possible that depressive symptoms in PDA contribute to negative expectancies.

There may be important implications for treatment process and outcome in patients suffering from PDA with depression. Cognitive-behavior therapy appears to be the most commonly used and effective psychotherapy for PDA patients. In fact, efficacy rates have been reported as high as 80 to 90\% (see Margraf et al., 1993). Other, findings, nevertheless, show that many panic disorder patients still experience substantial anxiety (Klosko et al., 1990) and approximately half of the patients experience a reoccurrence of panic attacks two years after CBT (Brown and Barlow, 1995). Expectancies and depressive symptoms may be factors to consider when the effectiveness of CBT is examined.

These findings may suggest that CBT is not effective for some PDA patients. Perhaps, PDA patients with depression may benefit less from CBT if their expectations are not addressed at the outset of therapy. Addressing expectations early on in treatment may decrease anxiety about undergoing therapy and improve treatment efficacy. The treatment may be appropriately tailored to deal with specific expectations (i.e., anxiety expectancy, anxiety sensitivity, and process expectations) of those with PDA and depressive symptoms. By addressing the negative cognitive styles, including their expectations, early on in therapy there may be positive or congruent shifts in the different types of expectations from pretherapy to the early-stages of treatment. Such cognitive shifts may prove to be important for the long-term outcome of panic disorder with agoraphobia. 


\section{References}

Abramson, LY, Seligman, MEP, Teasdale, J. 1978. Learned helplessness in humans; Critique and reformulation of depression. Psychol Rev 96:358-372.

American Psychiatric Association. 1994. Diagnostic and Statistical Manual of Mental Disorders $4^{\text {th }}$ ed. Washington D.C.

Andrade, L, Eaton, WW, Chilcoat, H. 1994. Lifetime comorbidity of panic attacks and major depression in a population-based study. Br J Psychiatry 165:363-369.

Bachelor, A., Bleau, P., \& Raymond, D. (1996). Cognitive and psychodynamic correlates of depressive symptomatology. Psychological Reports, 75(3 pt 1), 824-826.

Beck, AT, Epstein, N, Brown, G, Steer, RA. 1988. An inventory for measuring clinical anxiety: Psychometric properties. J Consult Clin Psychol 56:893-897.

Beck, AT, Rush, AJ, Shaw, BF, Emery, G. 1979. Cognitive therapy of depression. New York: Guilford Press.

Beck, AT, Steer, RA, Brown, GK. 1996. Beck Depression Inventory Second Edition: Manual. San Antonio, TX: Psychological Corporation.

Brown, TA, Barlow, DH. 1995. Long-term outcome in cognitive-behavioral treatment of panic disorder: Clinical predictors and alternative strategies for assessment. J Consult Clin Psychol 63:754-765.

Bourque, P, Beaudette, D. 1982. Étude psychométrique du questionnaire de dépression de Beck auprès d'un échantillon d'étudiants universitaires francophones. Revue canadienne des sciences du comportement 14:211-218.

Burns, MO, Seligman, MEP. 1991. Explanatory style, helplessness and depression, In Snyder, CR, Forsyth, DR. (Eds), Handbook of social and clinical psychology: The health perspective. Elmsford, New York: Pergamon Press. p 267-284.

Chambless, DL. 1985. The relationship of severity of agoraphobia to associated psychopathology. Behav Res Ther 23:305-310.

Chambless, D L, Caputo, GC, Bright, P, Gallagher, R. 1984. Assessment of fear in agoraphobics: The Body Sensations Questionnaire and the Agoraphobic Cognitions Questionnaire. J Consult Clin Psychol 52:1090-1097. 
Chambless, DL, Caputo, GC, Jasin, SE, Gracely, EJ, Williams, C. 1985. The Mobility Inventory for Agoraphobia. Behav Res Ther 23:35-44.

Clark, DM, Salkovskis, PM, Hackmann, A, Middleton, H, Anastasiades, PA, Gelder, M. 1994. A comparison of cognitive therapy, applied relaxation and imipramine in the treatment of panic disorder. Brit J Psychiatry 164:759-769.

Cohen, L, de Moor, C, Amato, RJ. 2001. The association between treatment-specific optimism and depressive symptomatology in patients enrolled in a Phase I cancer clinical trial. Cancer 91:1949-1955.

Cox, BJ, Enns, MW, Freeman, P, Walker, JR. 2001. Anxiety sensitivity and major depression: examination of affective state dependence. Behav Res Ther 39:1349-1356.

Cox, BJ, Parker, JDA, Swinson, RP. 1996. Anxiety sensitivity: Confirmatory evidence for a multidimensional construct. Behav Res Ther 34:591-598.

Deane, F.P., Spicer, J., \& Leathem, J. (1992). Effects of videotaped preparatory information on expectations, anxiety, and psychotherapy outcome. Journal of Consulting and Clinical Psychology, 60(6), 980-984.

DiNardo, PA, Brown, TA, Barlow, DH. 1994. Anxiety Disorders Interview Schedule for DSMIV: Lifetime version (ADIS-IV-L). Albany, NY: Graywind Publications.

Duckro, P., Beal, D., \& George, C. (1979). Research on the effects of disconfirmed client role expectations in psychotherapy: a critical review. Psychological Bulletin, 86, 260-275.

Freeston, M.H., Ladouceur, R., Thibodeau, N., Gagnon, F., Rhéaume, J. 1994. The Beck Anxiety Inventory. Psychometric properties of a French translation. Encephale 20(1): 4749.

Furham, A, Wardley, Z. 1990. Lay theories of psychotherapy I: Attitudes toward, and beliefs about, psychotherapy and therapists. J Clin Psychol 46:878-890.

Furham, A, Wardley, Z, Lillie, F. 1992. Lay theories of psychotherapy III: Comparing the ratings of lay persons and clinical psychologists. Human Relations 45:839-857.

Gauthier, J, Morin, C, Thériault, F, Lawson, J S. 1982. Adaptation française d'une mesure d'auto-évaluation de l'intensité de la dépression. Revue québécoise de psychologie 3:13-27. 
Goldstein, AP. 1962. Therapist-patient expectancies in psychotherapy. New York: Pergamon Press.

Katerelos, TE, Bélanger, C, Perreault, M. 1998. Process Expectations Questionnaire. Unpublished manuscript, Université du Québec à Montréal.

Katerelos, TE, Perreault, M, Bélanger, C. 1998. The Expectancy Mobility Inventory for Agoraphobia-Alone. Unpublished manuscript, Université du Québec à Montréal.

Klosko, JS, Barlow, DH, Tassinari, R, Cerny, JA.1990. A comparison of alprazolam and behavior therapy in the treatment of panic disorder. J Consult Clin Psychology 58:77-84.

Kunkel, MA, Hector, MA, Gongóra Coronado, E, Castillo Vales, V. 1989. Expectations about counseling in Yucatán, Mexico: Toward a "Mexican Psychology". J Counseling Psychol 36:322-330.

Kushner, MG, Sher, KJ. 1989. Fear of psychological treatment and its relation to mental health service avoidance. Professional Psych: Res Practice 20:254-257.

Marcaurelle, R, Katerelos, TE. 1998. The Symptom Expectancy Questionnaire. Unpublished manuscript, Université du Québec à Montréal.

Marchand, L, Stephenson, R, Feeney, S, Marchand, A. 1999. Validation factorielle de l'adaptation canadienne-française de l'Anxiety Sensitivity Scale. Poster session presented at the "congrès de l'Association Canadienne Française pour l'Avancement des Sciences (ACFAS)", Ottawa, Ontario, 10-14 mai.

Margraf, J, Barlow, DH, Clark, DM, Telch, MJ. 1993. Psychological treatment of panic: Work in progress on outcome, active ingredients, and follow-up. Behav Res Ther 31:1-8.

Mezydlo Subich, L, Coursol, DH. 1985. Counseling expectation of clients and nonclients for group and individual treatment modes. J Counseling Psychol 32:245-251.

Otto, MW, Pollack, MH, Fava, M, Uccello, R, Rosenbaum, JR. 1995. Elevated Anxiety Sensitivity Index scores in patients with major depression: Correlates and changes with antidepressant treatment. J Anxiety Disord 9:177-123.

Reiss, S, Peterson, RA, Gursky, DM, McNally, RJ. 1986. Anxiety sensitivity, anxiety frequency, and the prediction of fearfulness. Behav Res Ther 24:1-8. 
Regier, DA, Rae, DS, Narrow, WE, Kaelber, CT, Schatzberg, AF. 1998. Prevalence of anxiety disorders and their comorbidity with mood and addictive disorders. $\mathrm{Br} \mathrm{J}$ Psychiatry 173:24-28.

Renneberg, B, Chambless, DL, Gracely, EJ. 1992. Prevalence of SCID-diagnosed personality disorders in agoraphobia outpatients. J Anxiety Disord 6:111-118.

Roy-Byrne, P, Stang, P, Wittchen, HU, Ustun, B, Walters, E, Kessler, RC. 2000. Lifetime, panic-depression comorbidity in the National Comorbidity Survey. $\mathrm{Br} J$ Psychiatry 176:229-235.

Safren, S.A., Heimberg, R.G., \& Juster, H.R. (1997). Client's expectancies and their relationship to pretreatment symptomatology and outcome of cognitive-behavioral group treatment for social phobia. Journal of Consulting and Clinical Psychology, 65(4), 694-698.

Schmidt, NB, Lerew, DR, Joiner, TE Jr. 1998. Anxiety sensitivity and the pathogenesis of anxiety and depression: Evidence for symptom specificity. Behav Res Ther 36:165-177.

Seligman, MEP. 1975. Helplessness: On depression, development, and death. San Francisco: W.H. Freeman.

Stein, MB, Tancer, ME, Uhde, TW. 1990. Major depression in patients with panic disorder: factors associated with course and recurrence. J Affect Disord 19:287-96.

Stephenson, R, Marchand, A, Lavallée, MC. 1997. Validation de I'Inventaire de mobilité pour l'agoraphobie auprès de la population québécoise francophone. Science et comportement 26:35-58.

Stephenson, R, Marchand, A, Lavallée, MC. 1998. Validation du questionnaire des sensations physiques auprès de la population canadienne-française. L'Encéphale 24:415-425.

Stephenson, R, Marchand, A, Lavallée, MC. 1999. A Canadian French Adaptation of the Agoraphobic Cognitions Questionnaire: Cross-cultural validation and gender differences. Scand J Behav Ther 28:58-69.

Taylor, S. 1993. The structure of fundamental fears. J Behav Ther Exp Psychol 24:289-299.

Taylor, S, Koch, WJ, Woody, S, McLean, PD. 1996. Anxiety sensitivity and depression: How are they related? J Abnorm Psychol 105:474-479. 
Tinsley, HEA, Brown, MT, St Aubin, TM, Lucek, J. 1984. Relation between expectancies for a helping relationship and tendency to seek help from a campus help provider. J Counseling Psychol 31:149-160.

Tsao, JC, Lewin, MR, Craske, MG. 1998. The effects of cognitive-behavior therapy for panic disorder on comorbid conditions. J Anxiety Disord 12:357-371.

Vallerand, RJ. 1989. Vers un méthodologie de validation trans-culturelle de questionnaires psychologiques: implications pour la recherche en langue Française. Can Psychol 30:662-680.

Vasile, RG, Goldenberg, I, Reich, J, Goisman, RM, Lavori, PW, Keller, MB. 1997. Panic disorder versus panic disorder with major depression; defining and understanding differences in psychiatric morbidity. Depress Anxiety 5:12-20.

Whittal, ML, Goetsch, VL. 1997. The impact of panic expectancy and social demand on agoraphobic avoidance. Behav Res Ther 36:813-821.

Zwick, R, Attkisson, CC. 1985. Effectiveness of a client pretherapy orientation videotape. J Counseling Psychol 32:514-524.

Zwick, R, Attkisson, CC. 1984. The use of reception checks in client pretherapy orientation research. J Clin Psychol 40:446-452.

\section{About the authors}

Dr. Theodora E. Katerelos completed her Ph.D at the University of Quebec in Montreal, under the direction of Dr. Bélanger and Dr. Perreault. Her primary research interests focus on anxiety disorders.

Dr. Michel Perreault (corresponding author) is associate professor at McGill University and a researcher at the Douglas Mental Health Institute. His studies are centered on patient expectations and satisfaction toward treatment measures.

Address for correspondence: Dr Perreault, Institut de santé mentale Douglas 6875 boul. LaSalle, Montréal, Québec, Canada H4H 1 R3

E-mail: michel.perreault@douglas.mcgill.ca 
Dr. Claude Bélanger is a full professor and director of the laboratory for the study of anxiety disorders at the University of Quebec in Montreal, as well as assistant professor in the Psychiatry Department at McGill University. He is also involved as a clinician and researcher in the Anxiety Clinic at the Douglas Mental Health University Institute. His primary research interests include anxiety disorders as well as predictors of efficacy for treatment of panic disorder.

Dr. André Marchand is a full professor at the University of Quebec in Montreal, and codirector of the laboratory on trauma studies at L.H. Lafontaine hospital. His primary research interests focus on anxiety disorders as well as predictors of efficacy for treatment of these disorders.

Dr. John Pecknold is a psychiatrist, assistant professor at McGill University and head of the Anxiety Clinic at the Douglas Mental Health University Institute. 